\title{
Anatomy of Teaching Anatomy: Do Prosected Cross Sections Improve Students Understanding of Spatial and Radiological Anatomy?
}

\author{
L. B. Samarakoon, S. Vithoosan, S. Kokulan, M. M. Dissanayake, D. J. Anthony, \\ Vajira Dissanayake, and Rohan Jayasekara \\ Department of Anatomy, Faculty of Medicine, University of Colombo, No. 25, Kynsey Place, 00800 Colombo, Sri Lanka \\ Correspondence should be addressed to L. B. Samarakoon; lasithamfc@gmail.com and D. J. Anthony; drdjanthony@gmail.com
}

Received 14 May 2016; Accepted 11 July 2016

Academic Editor: Erich Brenner

Copyright (c) 2016 L. B. Samarakoon et al. This is an open access article distributed under the Creative Commons Attribution License, which permits unrestricted use, distribution, and reproduction in any medium, provided the original work is properly cited.

Introduction. Cadaveric dissections and prosections have traditionally been part of undergraduate medical teaching. Materials and Methods. Hundred and fifty-nine first-year students in the Faculty of Medicine, University of Colombo, were invited to participate in the above study. Students were randomly allocated to two age and gender matched groups. Both groups were exposed to identical series of lectures regarding anatomy of the abdomen and conventional cadaveric prosections of the abdomen. The test group $(n=77$, $48.4 \%)$ was also exposed to cadaveric cross-sectional slices of the abdomen to which the control group $(n=82,51.6 \%)$ was blinded. At the end of the teaching session both groups were assessed by using their performance in a timed multiple choice question paper as well as ability to identify structures in abdominal CT films. Results. Scores for spatial and radiological anatomy were significantly higher among the test group when compared with the control group $(P<0.05$, CI 95\%). Majority of the students in both control and test groups agreed that cadaveric cross section may be useful for them to understand spatial and radiological anatomy. Conclusion. Introduction of cadaveric cross-sectional prosections may help students to understand spatial and radiological anatomy better.

\section{Introduction}

Cadaveric prosections have been fundamental to understanding the complexities of the human body structure and have played a pivotal role in gross anatomy teaching in medical education [1]. Dissection of cadavers provides student with the unique perception of intricacies of human anatomy that is thought to facilitate understanding of complex visuospatial relationships of the human body [2]. Unfortunately the scarcity of cadavers, adverse student cadaver ratio, and increasingly shorter courses have made cadaveric dissection redundant from anatomy curricula [3]. An increasing number of computer assisted learning tools (CAL) have been introduced to fill in the practical aspects of teaching human anatomy [4-6]. In the absence of cadaveric dissection, prosected specimens have increasingly been used in teaching anatomy to medical undergraduates [7]. Newer techniques like plastination have been developed and used increasingly. With the advent of sophisticated imaging modalities such as 3D CT reconstructions, high resolution cadaveric CT scans have found its way to anatomy laboratories [8]. Introduction of ultrasound in anatomy teaching session has been received with much enthusiasm [9].

Traditionally anatomy has been taught on a regional basis. However cross-sectional anatomy is routinely encountered by clinicians. With the advent of modern medical imaging, more and more cross-sectional images of human anatomy are available as teaching material for modern day students. Can we improve spatial understanding of anatomy and imaging by exposing students to cadaveric cross-sectional specimens? We attempted to answer this question in a carefully designed case control study. 
TABLE 1: Basic demographic data for the test and control.

\begin{tabular}{|c|c|c|c|}
\hline & Male & Female & Mean age (years) \\
\hline Control group & $40(48.8)$ & $42(51.2)$ & 21.3 \\
\hline \multirow[t]{2}{*}{ Test group } & $44(57.1)$ & $33(42.9)$ & 20.9 \\
\hline & $84(52.8 \%)$ & 75 (47.2\%) & \\
\hline
\end{tabular}

TABLE 2: Comparison of scores between test and control groups value $P<0.05$, CI 95\%.

\begin{tabular}{lccc}
\hline & Control group & Test group & $P$ value \\
\hline RA & $25.85[\mathrm{SD}=11.05]$ & $42.01[\mathrm{SD}=3.99]$ & $<0.05$ \\
SA & $33.40[\mathrm{SD}=7.35]$ & $37.59[\mathrm{SD}=4.43]$ & $<0.05$ \\
CS & $58.89[\mathrm{SD}=13.55]$ & $79.29[\mathrm{SD}=6.54]$ & $<0.05$ \\
\hline
\end{tabular}

RA: radiological anatomy, SA: spatial anatomy, and CS: combined scores.

TABLE 3: Subgroup analysis of the mean scores of control and test groups.

\begin{tabular}{|c|c|c|c|}
\hline & Male & Female & $P$ value \\
\hline \multicolumn{4}{|c|}{ Control } \\
\hline RA & $\begin{array}{c}28.30 \\
(\mathrm{SD} 11.50)\end{array}$ & $\begin{array}{c}23.52 \\
(\mathrm{SD} 10.21)\end{array}$ & 0.0502 \\
\hline SA & $\begin{array}{c}33.40 \\
(\mathrm{SD} 6.98)\end{array}$ & $\begin{array}{c}33.40 \\
(\mathrm{SD} 7.78)\end{array}$ & 0.9952 \\
\hline CS & $\begin{array}{c}61.70 \\
\text { (SD 14.93) }\end{array}$ & $\begin{array}{c}56.92 \\
\text { (SD 11.95) }\end{array}$ & 0.1172 \\
\hline \multicolumn{4}{|l|}{ Test } \\
\hline RA & $\begin{array}{c}42.04 \\
(\mathrm{SD} 3.78)\end{array}$ & $\begin{array}{c}41.97 \\
(\mathrm{SD} 4.32)\end{array}$ & 0.941 \\
\hline SA & $\begin{array}{c}37.18 \\
(\mathrm{SD} 4.82)\end{array}$ & $\begin{array}{c}38.15 \\
(\mathrm{SD} 3.85)\end{array}$ & 0.3318 \\
\hline CS & $\begin{array}{c}79.22 \\
(\mathrm{SD} 6.58)\end{array}$ & $\begin{array}{c}79.39 \\
(\mathrm{SD} 6.60)\end{array}$ & 0.9164 \\
\hline
\end{tabular}

\section{Materials and Methods}

Hundred and fifty-nine (male $n=84,52.8 \%$ female $n=$ $75,47.2 \%$ ) first-year students in the Faculty of Medicine, University of Colombo, were invited to participate in the above study. Written informed consent was obtained and the consenting students were randomly allocated to two age and gender matched groups. Both groups were exposed to identical series of lectures regarding anatomy of the abdominal cavity. Control group was exposed to conventional cadaveric prosections of the abdomen. The test group $(n=$ $77,48.4 \%)$ was exposed to a session containing prosected cadaveric cross-sectional slices of the abdomen to which the control group $(n=82,51.6 \%)$ was blinded. At the end of the teaching session understanding of the spatial anatomy of the abdomen among both groups was assessed by using their performance in a timed pretested and validated multiple choice question paper (SA). In addition ability to identify structures in abdominal CT films was also tested in a structured examination using abdominal CT scan films (RA). Individual marks of each component were added to arrive at the final cumulative scores (CS).

\section{Ethical Considerations}

Written informed consent was obtained from all participants. Ethics clearance was obtained from University of Colombo Ethics Committee.

\section{Results}

4.1. Demography (Table 1). 159 (male $n=84,52.8 \%$ female $n=75,47.2 \%$ ) first-year medical students participated in the study. Male female distribution and mean age were nearly equal in both groups.

4.2. Scores for Spatial and Radiological Anatomy (Table 2). Scores for spatial anatomy (SA) and radiological anatomy (RA) as well as the cumulative scores (CS) were higher among the test group when compared with the control group. Differences observed among the scores were statistically significant $(P<0.05$, CI 95\%).

Subgroup analysis among control and test groups failed to reveal any statistically significant difference in scores between male and female students.

4.3. Perceptions (Table 3). After the quiz was completed, control group was also exposed to a brief session of prosected cross-sectional specimens similar to the test group, and both groups were requested to complete the perceptions section. Majority of the students in both control and test groups agreed that cadaveric cross section may be useful for them to understand spatial and radiological anatomy $(97.6 \%$ and $98.7 \%$, resp.). Similarly vast majority in both groups (control 97.6\% test $97.4 \%$ ) also thought that radiological imaging may be used more often as adjunct to teaching anatomy.

\section{Discussion}

Sound knowledge of anatomy has been considered cornerstone of medical education [10]. This is especially true in surgical education where clear understanding of spatial relationship of structures with one another is extremely important. Even though increasingly less time is devoted to teaching anatomy in conventional curricula, clinicians are exposed to more and more cross-sectional anatomy with the sophistication of the medical imaging [11].

Certainly the concept of using cross-sectional imaging as an adjunct for teaching anatomy is not new. As early as $1985,68 \%$ of medical schools in the United States were using some form of radiological imaging in undergraduate teaching [12]. Over time the imaging modalities used for teaching has changed with the changing trends of practice of medicinepredominantly plain X-rays and fluoroscopy [13] evolving onto cross-sectional imaging such as CT and MRI [11]. Some medical schools have taken this approach to the extreme with completely doing away with cadaveric dissection/prosections from the curricula, exclusively relying on medical imaging [14], although many would argue against such a radical shift from the established teaching practices [15].

Early ingenious attempts have been made to incorporate cross-sectional anatomy into medical curricula. Oh and 
colleagues used clay models of internal organs and used cut surfaces of the models to teach students how to interpret cross-sectional diagnostic imaging [16]. Plastic models have been used in the early days to circumvent problems associated with cadaveric dissection [14]. Interestingly body painting has been used to promote understanding of surface anatomy and its relation with underlying structures [17]. With the advancement of plastination an effective technique for tissue preservation, more and more plastinated cross sections were introduced onto cadaveric anatomical courses [18]. With further advancement of technology, computer assisted learning (CAL) was introduced. Term anatomical informatics was introduced in 2002 by Trelease. Various web based applications and computer based software have been developed to aid the student to grasp key anatomical concepts. Indeed it has been shown that students who had access to computer based anatomical programs scored consistently higher in professional examinations [19]. Utilization of modern technology in teaching anatomy has been uplifted to a new level by the advent of visible human anatomy projects $[5,6]$.

In our study we noted statistically significant improvement in spatial anatomical scores as well as radiological anatomy interpretation scores when students were exposed to cadaveric cross sections. Although there are multiple reviews on use of cross-sectional radiological imaging material as teaching aids for students [12-14], hardly any exist which objectively look at the utility of cadaveric cross sections, in improving students spatial understanding of anatomical structures. Indeed modern medical imaging relies heavily on cross-sectional anatomy, and it is logical to incorporate cadaveric cross sections into preclinical anatomy curricula. Due to this fact, test group students who were exposed to cross-sectional prosections scored significantly higher marks in interpretation of radiological imaging also.

Our study also explored the perceptions of the students regarding use of cadaveric cross-sectional imaging in anatomy teaching. Interestingly enough, significant proportion of both test and control groups thought that crosssectional prosections may be extremely helpful in understanding anatomical concepts. Even though we did not use imaging as a teaching tool in our study, majority of both test and control groups felt that radiological imaging would be a useful adjunct to learning anatomy. This is in keeping with many other studies where integration of radiological anatomy to traditional anatomy courses was received with welcome arms by both students and instructors [9].

Although we propose to use cadaveric prosections and radiological imaging as an adjunct to conventional anatomy teaching we still do not advocate sole reliance of crosssectional imaging for purposes of teaching anatomy. Indeed there have been rising concerns regarding falling quality of anatomical education with ever decreasing course times and limited availability of cadavers for dissection [15]. Although hybrid teaching with imaging material will undoubtedly aid conceptual understanding and retention of facts, it should not be considered a substitute for conventional cadaver based anatomy courses [20].

\section{Conclusion}

Our study illustrates that cadaveric cross-sectional prosections can be used as an adjunct to improve spatial anatomical knowledge among students and to improve the ability to accurately interpret the radiological imaging. We recommend incorporation of prosected cadaveric cross sections as well as radiological imaging material as adjuncts to conventional anatomical curricula.

\section{Abbreviations}

CT: Computed Tomography

MRI: Magnetic Resonance Imaging

SA: Spatial anatomy

RA: Radiological anatomy

CS: Cumulative scores

CAL: Computer assisted learning.

\section{Competing Interests}

The authors declare that they have no competing interests.

\section{Authors' Contributions}

L. B. Samarakoon conceptualized and planned the project. L. B. Samarakoon, S. Vithoosan, and S. Kokulan gathered and analyzed data. L. B. Samarakoon prepared the initial paper. M. M. Dissanayake, D. J. Anthony, Vajira Dissanayake, and Rohan Jayasekara made critical revisions to the paper. All authors read and approved paper.

\section{Acknowledgments}

The authors would like to acknowledge the assistance of Mr. R. Kulendaran (Technician of the Anatomy laboratory) in preparing the cross-sectional prosections.

\section{References}

[1] J. C. McLachlan and D. Patten, "Anatomy teaching: ghosts of the past, present and future," Medical Education, vol. 40, no. 3, pp. 243-253, 2006.

[2] J. C. McLachlan, J. Bligh, P. Bradley, and J. Searle, "Teaching anatomy without cadavers," Medical Education, vol. 38, no. 4, pp. 418-424, 2004.

[3] J. K. Gregory, N. Lachman, C. L. Camp, L. P. Chen, and W. Pawlina, "Restructuring a basic science course for core competencies: an example from anatomy teaching," Medical Teacher, vol. 31, no. 9, pp. 855-861, 2009.

[4] B. Temkin, E. Acosta, A. Malvankar, and S. Vaidyanath, "An interactive three-dimensional virtual body structures system for anatomical training over the internet," Clinical Anatomy, vol. 19, no. 3, pp. 267-274, 2006.

[5] J. S. Park, M. S. Chung, S. B. Hwang, B.-S. Shin, and H. S. Park, "Visible Korean human: its techniques and applications," Clinical Anatomy, vol. 19, no. 3, pp. 216-224, 2006.

[6] S.-X. Zhang, P.-A. Heng, and Z.-J. Liu, "Chinese visible human project," Clinical Anatomy, vol. 19, no. 3, pp. 204-215, 2006. 
[7] J. P. Collins, "Modern approaches to teaching and learning anatomy," British Medical Journal, vol. 337, Article ID a1310, 2008.

[8] O. Durosaro, N. Lachman, and W. Pawlina, "Use of knowledgesharing web-based portal in gross and microscopic anatomy," Annals of the Academy of Medicine Singapore, vol. 37, no. 12, pp. 998-1001, 2008.

[9] S. Rao, L. Van Holsbeeck, J. L. Musial et al., "A pilot study of comprehensive ultrasound education at the Wayne State University School of Medicine: a pioneer year review," Journal of Ultrasound in Medicine, vol. 27, no. 5, pp. 745-749, 2008.

[10] E. M. Bergman, C. P. M. Van Der Vleuten, and A. J. J. A. Scherpbier, "Why don't they know enough about anatomy? A narrative review," Medical Teacher, vol. 33, no. 5, pp. 403-409, 2011.

[11] I. Ganske, T. Su, M. Loukas, and K. Shaffer, "Teaching methods in anatomy courses in North American medical schools. The role of radiology," Academic Radiology, vol. 13, no. 8, pp. 10381046, 2006.

[12] L. W. Bassett and L. F. Squire, "Anatomy instruction by radiologists," Investigative Radiology, vol. 20, no. 9, pp. 1008-1010, 1985.

[13] T. H. Johnson Jr., "Medical school radiology teaching and examination methods," Radiology, vol. 93, no. 2, pp. 443-446, 1969.

[14] J. C. McLachlan, "New path for teaching anatomy: living anatomy and medical imaging vs. dissection," Anatomical Record-Part B: New Anatomist, vol. 281, no. 1, pp. 4-5, 2004.

[15] H. Ellis, "Teaching in the dissecting room," Clinical Anatomy, vol. 14, no. 2, pp. 149-151, 2001.

[16] C.-S. Oh, J.-Y. Kim, and Y. H. Choe, "Learning of cross-sectional anatomy using clay models," Anatomical Sciences Education, vol. 2, no. 4, pp. 156-159, 2009.

[17] C. T. Philip, K. P. Unruh, N. Lachman, and W. Pawlina, "An explorative learning approach to teaching clinical anatomy using student generated content," Anatomical Sciences Education, vol. 1, no. 3, pp. 106-110, 2008.

[18] R. Dhingra, V. Taranikanti, and R. Kumar, "Plastination: teaching aids in anatomy revisited," National Medical Journal of India, vol. 19, no. 3, article 171, 2006.

[19] J. A. McNulty, B. Sonntag, and J. M. Sinacore, "Evaluation of computer-aided instruction in a gross anatomy course: a sixyear study," Anatomical Sciences Education, vol. 2, no. 1, pp. 2-8, 2009.

[20] R. B. Gunderman and P. K. Wilson, "Viewpoint: exploring the human interior: the roles of cadaver dissection and radiologic imaging in teaching anatomy," Academic Medicine, vol. 80, no. 8, pp. 745-749, 2005. 

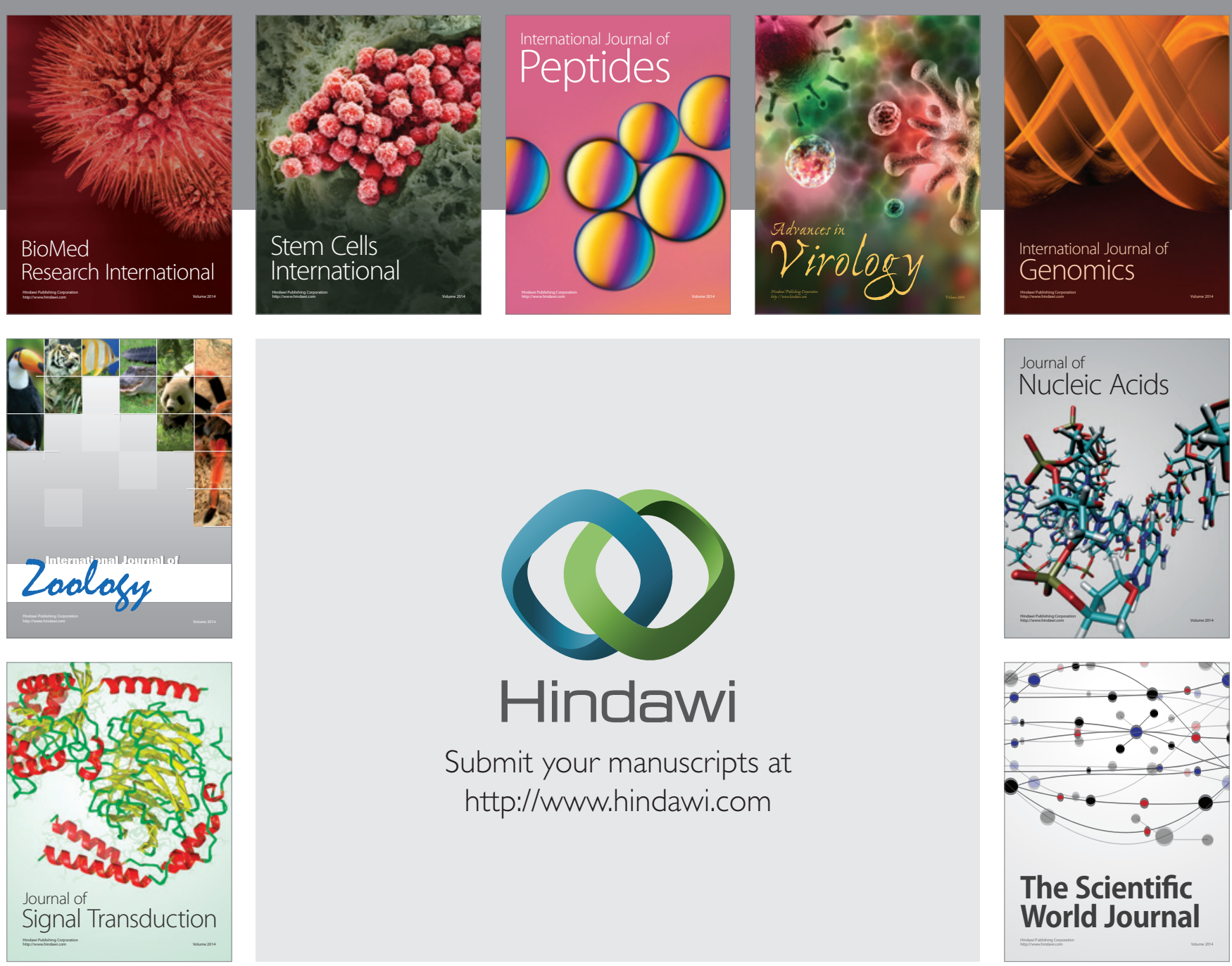

Submit your manuscripts at

http://www.hindawi.com
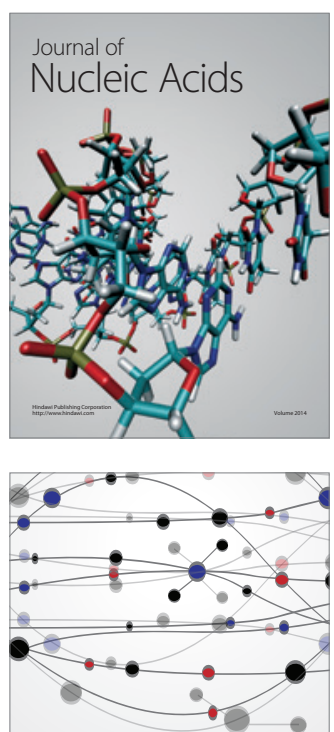

The Scientific World Journal
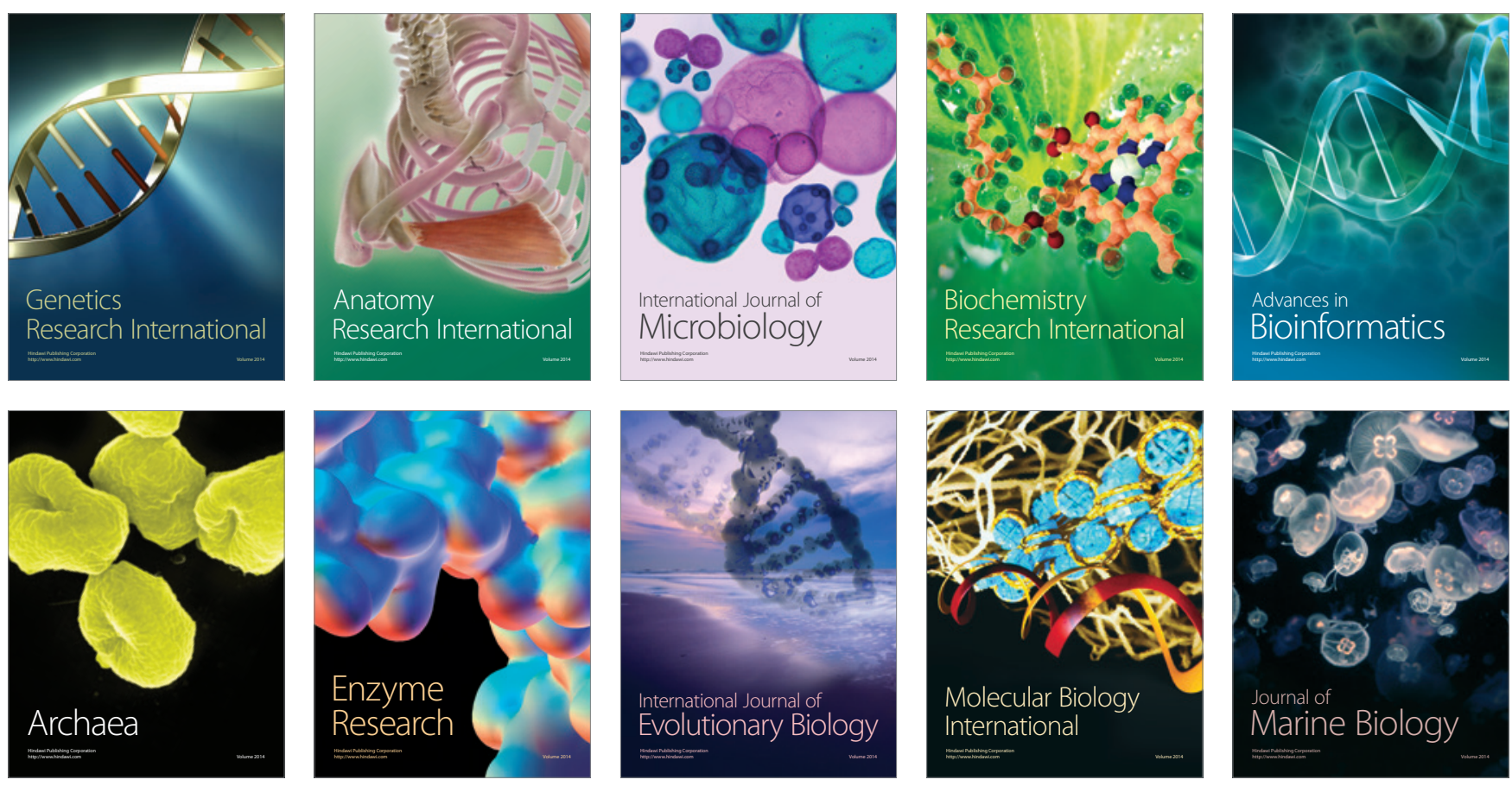